Copyright (C) 2014 by Academic Publishing House Researcher

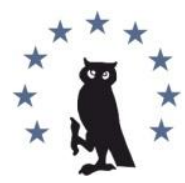

Published in the Russian Federation

European Researcher

Has been issued since 2010.

ISSN 2219-8229

E-ISSN 2224-0136

Vol. 85, No. 10-2, pp. 1874-188o, 2014

DOI: $10.13187 /$ er.2014.85.1874

www.erjournal.ru

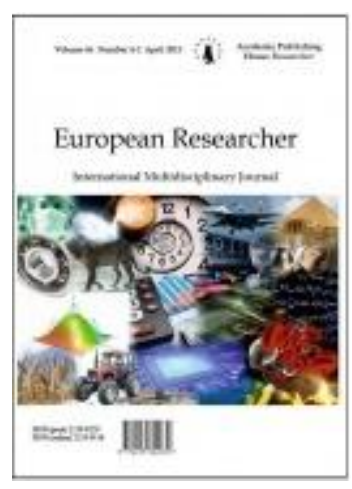

UDC 159.923 .5

\title{
Role of Temporal Transspective in Personality Formation of Adolescents Without Parental Support
}

\author{
${ }^{1}$ Dmitry V. Soldatov \\ ${ }^{2}$ Olga N. Zhiltsova
}

\author{
${ }^{1}$ Moscow State Regional Institute of Humanities, Russian Federation \\ 22, Zelenaya street, Orechovo-Zuevo city, Moscow region, 142611 \\ $\mathrm{PhD}$ (psychology), Assistant Professor \\ E-mail: soldatovdv@list.ru \\ 2 "Orehkovo-Zuevo Municipal \\ Social Rehabilitation Center for Non-adults, Russian Federation \\ 45, Gagarin street, Orechovo-Zuevo city, Moscow region, 142600. \\ pedagogue-phychologue \\ E-mail: olgazh73@rambler.ru
}

\begin{abstract}
Temporal transspective is understood as ability to connect in whole image of the past, present and future.

The article shows the results of a comparative study of temporal transspective of adolescents, whose personality formation takes place in different living conditions. Participants were 50 adolescents without parental support (experimental group) and 60 adolescents brought up in a family (control group). The research showed that temporal transspective of adolescents without parental support has not only peculiarities as gap between important events in the past, present and future, but as well such characteristics of their personalities as lack of confidence, ambivalency, anxiety, pessimism, moreover, motivation limited by nearest future.

Keywords: temporal transspective; the past; the present; the future; ambivalency; anxiety; optimism; pessimism; self-evaluation; motivation.

\section{Introduction}

Teenagers without parental support and therefore raised in state institutions, constitute a significant problem to society. This category of children is "anchored" in psychology and pedagogy as a typical "risk group" of deviant behavior, causing direct or consequential damage to society. But what brings these teenagers into a "risk group" of multiple adverse effects? What psychological "mechanisms" provoke destructive forms of their behavior? What important life relationships are impaired with adolescents in stable family deprivation?

Indeed, most teenagers without parental support, even as a child lived in the so-called "dysfunctional family", resulting an favorable process of forming their time perspectives images. However, deprived of even a small family support, they often get into public institutions, where
\end{abstract}


conditions conducive to mental development and personality formation, are not provided despite the efforts of the staff [7, 8]. Sometimes it happens, that children deprived of a full family, gradually become "psychologically handicapped", apparently due to special assessments of their own lives' perspectives. These children are forced to rethink, reevaluate their capabilities, desires and priorities in life. Most often this process is not satisfactory; as a result of life script "breakage", personality formation takes place under a special" social situation of development" (according to Vygotsky L.S.)

Difficult living conditions when adolescents have lost their families, leads to their personality formation distortion, in particular, because of a distorted perception of their own life time perspectives (the past, present and future) and transspective as a specific psychological phenomenon performing the ability of consciousness to connect in the present representation of the past and the future $[1,3,4]$.

Time perspectives images of own life are related to personality formation and human behavior at present $[6,15,16,17,18]$. At the moment some aspects of relations of time perspectives images of own life and personality characteristics of adolescents that live in families and outbred, are studied $[10,11,12,13]$.

However, the process of forming image about temporal transspective and its characteristics in different social groups, apparently being complex and deeply individual, is understudied.

\section{Methodology}

When studying the temporal transspective, the results obtained by using these psychological techniques, were reviewed, "Motivational induction method" (MIM) [5, 8], "Assessing five-year periods of life" [4], "Trait anxiety scale for 10-16 year-old students" [8], "Diagnostics of attitude to the past, present and future" [9], "Self-evaluation" (T. Dembo - S.Y. Rubinshtein), author's profile "Forecasting the Future ", author's questionnaire "Thoughts about future".

Estimation of statistical significance of empirical data relations was made using Pearson criteria $\chi^{2}$ and Ch. Spearman rank correlation coefficient [2].

\section{Participants}

110 adolescents living in Moscow region participated in the research; they were combined into two groups. The first group consisted of 50 teenagers from orphanages and shelters (experimental group). The second group was 60 adolescents brought up in families (control group). Samples had no significant differences in gender and age.

\section{Findings}

When analyzing the experimental results, some features of temporal transspective of adolescents without parental support, were found.

The first feature is that adolescents of experimental group have the line of transspective deformed in two places: the past is not related to the present, and the present - to the future.

A comparative analysis of participants' quantity of significant events of the past (five years period from 0-5 years, 6-10 years), present (11-15 years) and future (all remaining five years periods, starting from 16-20 years etc.) periods by procedure "Assessing five years periods of life".

Thus, there were no statistically significant associations by Spearman criteria of significant events quantity in the past, present and future, in the responses of adolescents of experimental group (Figure).

At the same time statistically significant correlations by Spearman criteria between the events of the past and present $\left(r_{s}=0.50, n=60 ; p=0,01\right)$; the past and future $\left(r_{s}=0.29, n=60 ; p=0,05\right)$, per quantity of significant events, were obtained in the responses of adolescents of control group. These data can be interpreted as follows: adolescents who are brought up in public institutions, have the quantity of past significant events not statistically linked to the quantity of significant events of the present and future. 


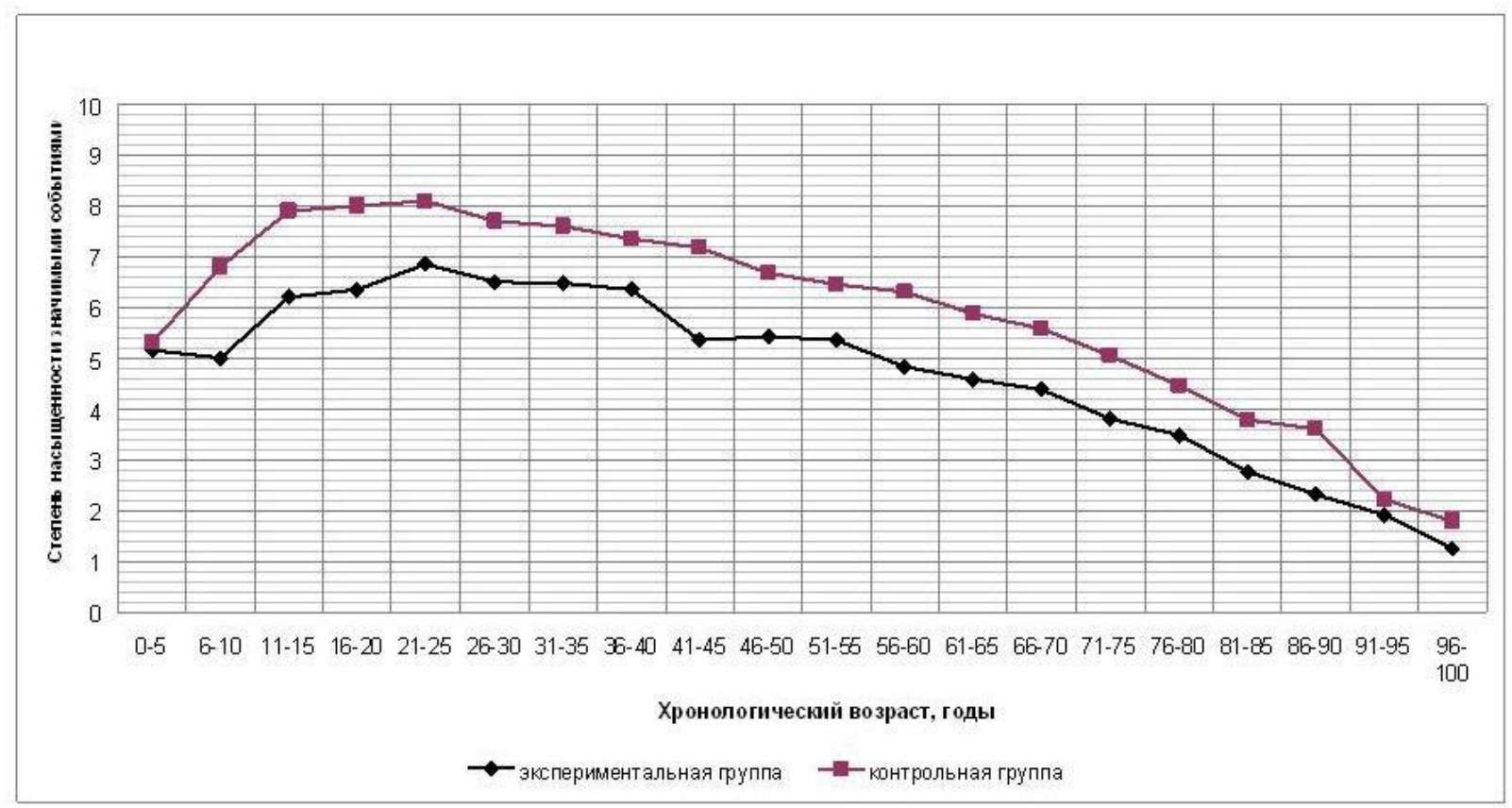

Fig. 1. Average quantity of significant events in five-year periods of life

The responses of adolescents outbred, by procedure "Assessing five-year periods of life", did not show statistically significant relation of significant events quantity in the present and future. In assessments of adolescents of the control group, the number of significant events in the present and future, statistically significant relationships by Pearson $\left(\chi^{2}{ }_{0.05}=4.51 ; \mathrm{v}=1\right)$ and by Spearman criteria $\left(\mathrm{r}_{\mathrm{s}}=0.38, \mathrm{n}=60 ; \mathrm{p}=0,01\right)$, were obtained. Consequently, teenagers left without family, underestimate the potential that the present has, to prepare positive events in the future.

Teenagers without parental support, predict a twice shorter period of their lives full of significant events compared to adolescents brought up in a family. Confirmation lies in the estimation reduction (below the median, $\mathrm{Md}=5,4$ ) of number of significant events in future of teenagers outbred, already after the age of 40. Teenagers who live in a family, "postpone" such a change in their lives to 70 years.

In addition, estimates of teenagers of the experimental group of number of significant events in life periods from 16 to 70 years and from 70 to 100 years (old age) did not show statistically significant relations. Whereas adolescents of the control group showed statistically significant correlations by Pearson $\left(\chi^{2}{ }_{0.01}=7.38 ; \mathrm{v}=1\right)$ and by Spearman $\left(\mathrm{r}_{\mathrm{s}}=0.51, \mathrm{n}=50 ; \mathrm{p}=0,01\right)$ criteria in the estimates of number of significant events in life periods from 16 to 70 years and from 70 to 100 years (old age). Thus, adolescents without family support have quantity of significant events life period from 16 to 70 years less related to quantity of significant events that may be in their life period from 70 to 100 . One can assume that adolescents without parental support are not inclined to consider the significant events of their adult lives as the basis of their well-being and activity at their old age.

Were obtained statistically significant differences in responses of the subjects of the experimental and control groups that reflected their attitude to the past, present and future $\left(X^{2}\right.$ o.01 $\left.=18.95 ; \mathrm{v}=1\right)$ by procedure "Diagnostics of attitude to the past, present and future". Most teenagers of the experimental group (54\%) show dominant contradictory attitude to the past, present and future, which is usually characterized by inconformity, a gap between them. While most adolescents in the control group (87\%) show dominant realistic, optimistic, consistent view of the past and future. Realistic, optimistic, consistent representation of the past and future is a favorable factor of full personality development in adolescence.

Thus, adolescents without parental support do not have the number of significant life events in different chronological periods in the past, present and future, connected. Meanwhile, the researchers note that one of the forms of unfavorable of the adolescent's personality development is an option when the past, present and future are isolated from each other. At present, the 
development of such a scenario is not derived from the past, and the future is not the continuation of the present [9].

The second feature of transspective representations is that outbred adolescents' appealing to memories of the past is associated with predicting financial problems. Were obtained statistically significant correlations by Pearson $\left(\chi^{2} 0.05=4.13 ; \mathrm{v}=1\right)$ between adolescents' thinking of the past (MIM) and prediction of financial problems in own's future (author's profile "Forecasting the Future"). Thus, the more often adolescents of the experimental group, reminisce, the less optimistic they are when assessing their financial security in the future. Adolescents of the control group, do not have such a relation.

The third feature of transspective representations is that their dissatisfaction with the way of life, is connected to externality, expression of hope and desire for self-realization in the future.

Thus, when analyzing results, the adolescents of the experimental group show relation between feeling dissatisfaction with the present and feelings, connected to anticipation of others' activity, their fate dependence on circumstances.

Statistically significant correlations by Pearson of adolescents without parental support, were obtained between dissatisfaction with the present and motives of hope "everything will be fine" in future - the category "expression of hope" "MIM" $\left(\chi^{2}{ }_{0.05}=4.73 ; \mathrm{v}=1\right)$. Adolescents, who live in the family, do not show such relationship.

Studies of mindsets for the future show that subjects who see their future as determined by circumstances (external attribution), as a rule, have their own activities with low instrumentality. That means, that teenagers who are not able to consider their studies as a tool for a future career, have a lower academic motivation. Therefore, we can state the impact of prospects of future on behavior in the present.

Such a trend cannot be considered constructive and it can contribute to deformation of the teenager's personality and formation of such traits as passivity, laziness, low motivation of activity, etc. It is believed that dissatisfaction with the way of life, leads to formation of illusions, hopes that in the future everything should change for the better, it is a kind of "wishful thinking". It should be noted that such expectations are often associated with social passivity of these adolescents.

Adolescents of the experimental group show statistically significant correlations by Pearson: between the experience of ill-being in the present and motivation of self-realization in the future in the category "self-realization" MIM ( $\chi^{2}$ o.05 $\left.=4.12 ; \mathrm{v}=1\right)$. Consequently, the experience of ill-being in the present cause the desire to "become somebody" in the future, i.e. self-realize. Adolescents of the control group do not show such a relation.

The fourth feature consists in connection of externality in the present and motivation of selfrealization in the future, with adolescents without parental support. The sample of adolescents who are brought up in public institutions, showed statistically significant correlations between the results of motivational tendencies associated not with a personal activity, but with the expectation of the activity of others, with a sense of their behavior and fate dependence on circumstances (category "aspiration of something from others" "Motivational induction method") and selfrealization motivation in the future (the category of "self-realization" "Motivational induction method": $\chi^{2}{ }_{0.05}=5.65 ; \mathrm{v}=1$ ). The paradoxical nature of this relation is that adolescents of the experimental group hope that in the future they will overcome the dependence on the circumstances that takes place in the present. Such expectations, in our view, can be considered as a compensatory mechanism to overcome difficult situations. We do not find such a relation with adolescents of the control group.

Thus, we can state that the peculiarity of transspective of adolescents outbred, is that their transspective lacks a constructed realistic connection between the past, present and future, there is no realistic and constructive time transspective "from success in the present - to success in the future".

The experimental group adolescents' experience of ill-being is associated with externality (dependence on external circumstances), expressing hope, that in the future everything will be fine and seeking for self-realization. Originality of the trasspective of adolescents without parental support, lies in a special way of adaptation to unfavorable situations in the present. Namely, some adolescents tend to hope for a future where "everything will be fine" and they will be able to selfrealize, by changing the external personality orientation, and others do believe that they are not able to change anything in their fate/life. 
Time transspective relation to some personality characteristics of adolescents without parental support

In our view, memories of teenagers of their past and visions of the future impact on the perception of the present and their personality formation. We analyzed how transspective is associated with certain personality traits, namely, self-esteem ("Self-evaluation" by T.Dembo S.Y. Rubinstein) anxiety ("Scale of personal anxiety for students 10-16 years" A.M. Prikhozhan), values, intrapersonal conflicts "Free choice of values", "Level ratio" values " and "accessibility" in various spheres of life" [14]. Analysis of ratings on the above test methods, allowed to identify a number of specific links between personality traits and transspective of adolescents without parental support.

The first feature is that the more often adolescents without parental support, are not selfsatisfied in the present, the more they discover the uncertainty about the future, the more ambivalent their visions of the future are, the more clear their desire to "quickly" graduate from school, is, the often they discover motives, limited by/with nearest future.

Statistically significant correlations by Pearson were obtained, in estimates of teenagers of the experimental group, between the uncertainty of what might happen in their future life (author profile "Thoughts about the future") and the degree of discrepancy between self-esteem and level of aspiration "Self-evaluation" $\left(\chi^{2}{ }_{0.05}=4.43 ; \mathrm{v}=1\right)$. Therefore, we can say: the less their degree of selfsatisfaction in the present, the more they tend to demonstrate the uncertainty that awaits them in the future.

Were obtained statistically significant correlations by Pearson in estimates of teenagers of the experimental group, between ambivalence in predicting future events (author profile "Thoughts about the future") and the degree of discrepancy between self-esteem and level of aspiration "Selfevaluation» $\left(\chi^{2}{ }_{0.05}=3.99 ; \mathrm{v}=1\right)$. Consequently, the less satisfied they are in the present, the greater uncertainty about the future they are experiencing. Adolescents of the control group do not show such a relation.

Were obtained statistically significant correlations by Pearson of estimates of adolescents of the experimental group, between motivational tendencies "to quickly graduate from school" "MIM" and the degree of discrepancy between self-esteem and level of aspiration, differentiation of selfesteem in the future «Self-evaluation» $\left(\chi^{2} 0.05=3.94 ; \mathrm{v}=1\right.$ and $\chi^{2} 0.05=4.61 ; \mathrm{v}=1$, respectively). Consequenly, the less the teenager is satisfied with him/herself in the present, the less stable is his/her estimation of own qualities in the future, the more they wish to graduate from school "as soon as possible". Adolescents of the control group do not show such relation.

In assessments of adolescents of the experimental group, were obtained statistically significant correlations by Pearson between representations about their nearest future (category of "nearest future", "MMI") and the degree of discrepancy between self-esteem and level of aspiration «Self-evaluation» $\left(\chi^{2}{ }_{0.05}=4.96 ; \quad v=1\right)$. Thus, the smaller the degree of self-satisfaction of adolescents without parental support, the more they discover statements reflecting their motives for the near future. Adolescents of the control group do not show such relation.

Thus, self-dissatisfaction as a personal trait is related to temporal transspective. Namely, with the uncertainty of the future, ambivalence of ideas about the future, with the desire to "quickly" graduate from school, with motives reflecting representations of their nearest future.

The second feature is that adolescents without parental support's, memories of the past are associated with general anxiety.

In assessments of adolescents of the experimental group, were obtained statistically significant correlations by Pearson $\left(\chi^{2}{ }_{0.05}=4.97 ; \mathrm{v}=1\right)$ between the motives that reflect memories of the past under "MIM" and general anxiety on the "Trait anxiety scale for 10-16 year-old students". In other words, the more disturbing experiences are in the present, the more teenagers living in state institutions are turning to memories of the past. Adolescents of the control group do not show such relation.

The third feature is that adolescents without parental support, are characterized by a combination of low self-evaluation in the present and future with forecasting low degree of saturation of significant events in the future.

Were obtained statistically significant correlations by Pearson of degree of saturation with significant events of life period from 16 to 70 years, "Assessing five-year periods of life" and general self-evaluation in the present and future, "Self-evaluation" of adolescents the experimental group, 
$\left(\chi^{2}\right.$ 0.01 $=7.93 ; \mathrm{v}=1 ; \chi^{2}{ }_{0.05}=5.42 ; \mathrm{v}=1$, respectively $)$. We can state that the lower adolescents outbred, assess their personality traits (abilities, character, beauty, intelligence, self-confidence) both in the present and in future, the less significant events they forecast in the period of life from 16 to 70 years, and vice versa. Adolescents, who live in the family, do not show such relation.

Consequently we can state the links between experience of psychological past, present, future and some personality characteristics of adolescents without parental support: general anxiety, selfevaluation in the present and estimation of own qualities in the future, self-satisfaction, differentiation of self-esteem in the future.

\section{Discussion}

It should be noted that there exist few works of temporal transspectiveand role ideas about the future in personality development of adolescents who are brought up in public institutions.

The researchers note that adolescents outbred cannot build a vision for the future and are therefore not able to perceive the relationship between present and future events, are not able to bind actual events of his/her future with the most important events of the past (А.М. Прихожан, H.Н. Толстых, 2007). Orphans face real contradictions between the need and the possibility of long-term planning of their lives that leads to distortion, reduction of life perspective, lack of plans for the future, their will to build them (Н.И. Федотова, 2008).

\section{Conclusion}

In our study, we found that adolescents outbred, are characterized by a subjective shortening of the period of active life. Temporal transspective is deformed, at least in two places: the past is not related to the present, and the present is not linked with the future. Our study adds the following conclusions to previous findings of temporal transspective of teenagers outbred: a more frequent appealing to memories of the past is associated with forecasting a lot of financial problems in their future; dissatisfaction with the present way of life is associated with externality, expression of hope and desire to self-realization in the future.

The majority of adolescents without parental support, find the following features in the estimates of temporal perspective: depreciation of the past, i.e. the period of life preceding adolescence, dissatisfaction with the way of life, prevalence of pessimistic assessments of possible future events, their illusory and ambivalent representaions, underestimation of past and present, as well as potential possessed by the future.

The study showed that such images of time perspective of adolescents without parental support, are associated with the uncertainty of the present and future, readiness to adverse events (mindset for adverse events in the future, "defeatist mood"), decreased activity and pessimism, underestimation of education role in ensuring future success (success in life ); insufficient willingness to overcome difficulties, to make efforts to achieve high goals, unrealistic goals; external personality; hidden anxiety.

Thus, the attitude of teenagers outbred, to various aspects of time perspectives, is related not by coincidence to the formation of their personality and behavior in the present.

\section{References:}

1. Abulkhanova K.A., Berezina T.N. Time personality and life time. Petersburg: Aleteya, 2001. (In Russian)

2. Ermolaev M.U. Mathematical statistics for psychologists: textbook. Moscow: MPSI: Flinta, 2003. 336 p. (In Russian)

3. Kovalev V.I. Peculiarities of personal time management life. // Humanistic problems of a psychological theory. Moscow, 1995. p. 179-185. (In Russian)

4. Kronic A.A., Akhmerov R.A. Capsomere. Methods of self-knowledge, psychodiagnostics and psychotherapy in psychology life path. Moscow, 2008. (In Russian)

5. Nuttin J. Motivation, action and future prospects. / Ed. D.A. Leontev. Moscow: Smysl, 2004. (In Russian)

6. Maslow A. Motivation and personality. Piter, 2008. (In Russian)

7. Persiyantseva S.V. Individual psychological peculiarities of the development of students in terms of family deprivation. / Social pedagogy. 2013. №3. P. 91-98. (In Russian) 
8. Prikhozhan A.M., Tolstykh N.N. The psychology of abandonment. Petersburg: Piter, 2007. 400 p. (In Russian)

9. Prikhozhan A.M. Psychology anxiety: pre-school and school age. Petersburg, 2009. 192 p. (In Russian)

10. Soldatov D.V., Zhiltsova O.N. Optimism and pessimism in juvenile imagination of the future. / Bulletin MGOU. A series of "Psychological science" Moscow: MGOU, 2010, №2. P. 22-28. (In Russian)

11. Soldatov D.V., Zhiltsova O.N. Psychological time of personality in adolescence. / Yaroslavl pedagogical Bulletin. Psycho-pedagogical science: scientific journal. Yaroslavl: YSPU, 2011. №2. Tom II. 267 p. (P. 247-252). (In Russian)

12. Tolstykh N.N. Chronotope: culture and ontogeny. Smolensk-Moscow, 2010. (In Russian)

13. Fedotova N.I. Ideas about life prospects of orphans (for example educational institutions of various types). / Abstract of thesis ... candidate of psychological Sciences. Moscow, 2008. (In Russian)

14. Fantalova E.B. The technique of "ratio "values" and "accessibility" in various spheres of life" // Journal of practical psychologist. 1996. №2. p. 32-37. (In Russian)

15. Frankl V. Man's search for meaning. Moscow: Progress, 1990. 368 p. (In Russian)

16. Menninger K. Hope // The American Journal of Psychiatry. 1959. Vol. 116. P. 481-491.

17. Weinstein Neil D. Unrealistic optimism about future life events // Journal of Personality and Social Psychology. Vol. 39 (5), Nov. 1980.

18. Wood J. V. Theory and research concerning social comparison of personal attributes // Psychological Bulletin. 1989. Vol. 106. P. 231-248. 